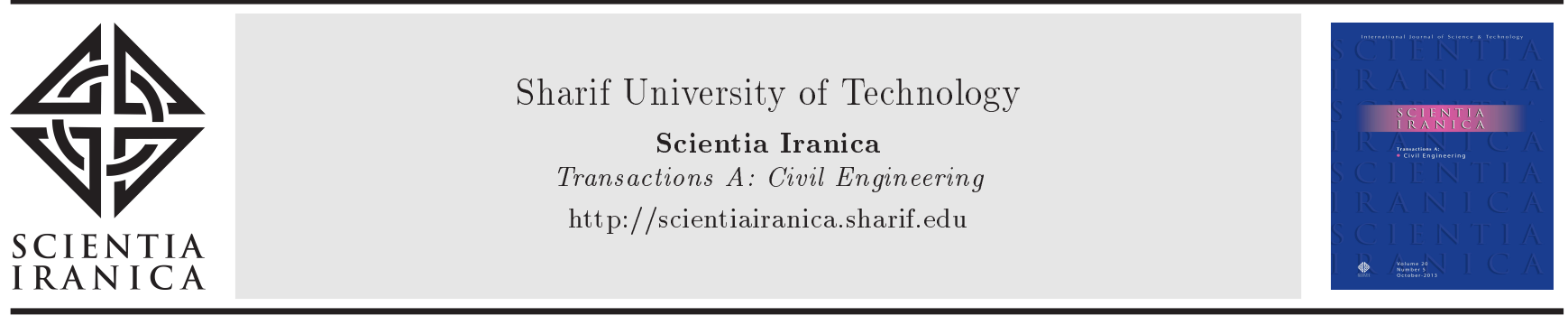

\title{
An experimental and numerical study on the mechanical behavior of Kunststof Lankhorst Product (KLP) sleepers
}

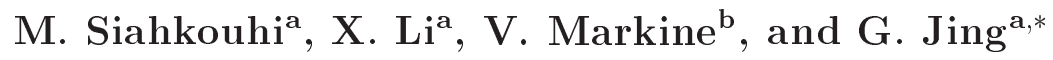 \\ a. School of Civil Engineering, Beijing Jiaotong University, Beijing 100044, China. \\ b. Department of Engineering Structures, Delft University of Technology, Postbus 5, 2600 AA Delft, the Netherlands.
}

Received 14 November 2020; received in revised form 14 January 2021; accepted 8 March 2021

\author{
KEYWORDS \\ Hybrid polymer \\ plastic sleeper; \\ KLP sleeper; \\ Railway ballasted \\ track; \\ Dynamic loading; \\ Finite element \\ method; \\ Three bending \\ moment test; \\ composite sleeper.
}

\begin{abstract}
In the present paper the mechanical behavior of two types of Kunststof Lankhorst Product (KLP) sleeper, namely low-density polyethylene sleeper (LDPE-16) and high-density polyethylene sleeper (HDPE-25) with $16 \mathrm{~mm}$ and $25 \mathrm{~mm}$ steel bars diameter, are studied. To this end, the static, dynamic, and longtime static three points bending moment tests are performed. The HDPE-25 and LDPE-16 with six strain gauges are mounted on the steel bars to assess their mechanical responses. Moreover, a Finite Element Method (FEM) model is developed to perform sensitivity analysis on $16 \mathrm{~mm}$ HDPE (HDPE-16) and $25 \mathrm{~mm}$ LDPE (LDPE-25) based on different steel bar diameters. The results showed that the LDPE-16 steel bar yielded under a load of $30 \mathrm{kN}$ for 4 hours, while HDPE-25 showed significant resistance. Numerical results showed that HDPE-25 is overdesigned and can be replaced by LDPE-25, which is lighter in weight and lower in price. The natural frequencies of HDPE-25 were almost $16 \%, 19 \%, 16 \%$, and $33 \%$ higher than the three first bending frequencies and first torsion frequency of LDPE-25, respectively. These findings prove the better performance of LDPE- 25 in the case of preventing resonance. In addition, the flexural modulus of HDPE- 25 was almost $42 \%, 45 \%$, and $65 \%$ higher than that of HDPE-16, LDPE-25, and LDPE-16, respectively.
\end{abstract}

(C) 2021 Sharif University of Technology. All rights reserved.

\section{Introduction}

Railway track components have been modified over the years such as ballast particles, fastening systems, and sleepers [1-3]. Railway sleepers are one of the important components of the railway track infrastructure. They have an important role in supporting the rails, providing sufficient horizontal and longitu-

*. Corresponding author. Tel.: +86-15901173048 E-mail addresses: m.siahkouhi@bjtu.edu.cn (M. Siahkouhi); 19121194@bjtu.edu.cn (X.Li);V.L.Markine@tudelft.nl (V. Markine); gqjing@bjtu.edu.cn (G. Jing)

doi: $10.24200 /$ sci.2021.57165.5096 dinal strength, and transferring forces from the rails to the ballast bed [4]. There are several types of sleepers, the most popular ones are made of timber, steel, and concrete. The timber sleepers have some shortcomings such as biodegradation (timber decay) and vulnerability to fire and insect pests, however always they are welcomed and since a long time they have kept their statute in the market [5]. Steel sleepers emerged as a substitute for timber sleepers. They have lighter weight, lower installation costs, and higher lateral resistance, but there are problems with corrosion and electrical isolation [6-8]. Compared with timber sleepers, concrete sleepers, as another alternative to railway track implementation, can provide greater strength to resist higher axle loads and longer 
durability. Jing et al. [9] recommended adding sensors to concrete sleepers to track the dynamic behavior of railway tracks. However, this type of sleeper also has its limitations in railway track operation, such as heavier weight, high initial cost, lower damping and ductility [10-12], and consumption of environmental natural resources [13]. Ferdous et al. [14] performed a comprehensive study on composite railway sleepers. Their findings show that due to the limited knowledge on the long-term and mechanical properties of the new composite sleepers and alternative materials for timber sleepers, their applications are reduced.

The history of the application of timber sleepers can be traced back to more than 150 years ago [15]. Currently, about 2.5 billion sleepers are used in railway networks in the world [16]. Timber sleepers have been used in the railway industry for a long time, especially in the United States [17] and Australia [18]. Several studies have evaluated the dynamic and static performance of timber sleepers [19-21]. Sadeghi and Barati [22] studied the performance of timber sleepers in a three bending test. The results showed that the timber sleeper deflection under a load of $30 \mathrm{kN}$ in the middle of the sleeper was about $4.2 \mathrm{~mm}$. Song et al. [23] investigated the pressure distribution of timber sleepers under cyclic loading. Their findings showed that under a cyclic load of about $40 \mathrm{kN}$, the timber sleeper faced a maximum pressure of about $0.13 \mathrm{MPa}$ in the middle of the sleeper. Several major failure causes of timber sleepers such as fungal decay, end splitting, and termite attack were proposed by Ferdous and Manalo [24]. These causes of damage have been treated with toxic chemicals to destroy harmful organisms in the timber, and plates have been installed at the ends of the timber sleepers to minimize their separation. Figure 1 shows some common defects of timber sleepers. Recently, due to lighter weight, higher thermal and electrical conductivity, higher corrosion resistance, damping ratio, and durability, composite
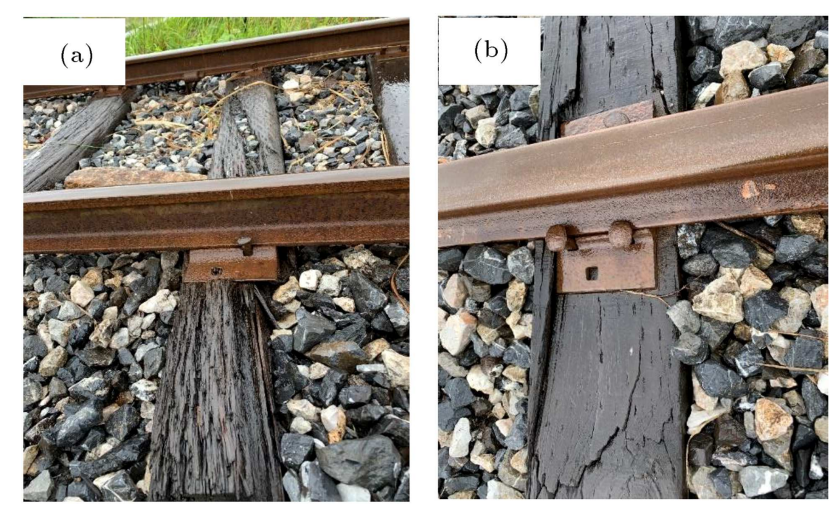

Figure 1. The timber sleepers defects mostly are seen in the field due to the (a) environmental effects and (b) overloading (Photo credit: G. Jing). sleepers have been increasingly used [25-27]. According to their geometric and mechanical properties, composite sleepers are mostly considered substitutes for timber sleepers, especially in key areas where damping and ductility characteristics are more required, such as turnouts [28], bridges [29,30], and tunnels [31]. Recently, a new generation of Kunststof Lankhorst Product (KLP) type of steel bar sleepers has been put on the market, which has sufficient mechanical properties to withstand high train axle loads. These sleepers have better elasticity, a low ballast abrasion index relative to the elastic contact between sleepers and ballast particles, and higher rail track lateral and longitudinal stability [32]. In addition, they provide higher durability, easier transportation and installation, and sustainability in solid waste plastic materials. These sleepers are based on a polymer matrix and are usually made of recycled plastic. The well-known available products are TieTek [33], Axion [34] and KLP [35] (see Figure 2). This kind of sleeper still needs more investigation; however, some studies have been conducted on this topic. In the ISO standard [36], the plastic sleepers are categorized into three material types of $\mathrm{A}, \mathrm{B}$, and $\mathrm{C}$, based on the track operational features such as train axle load and speed. The properties provided by material type A are similar to the properties of tropical hardwood sleepers, used for ballastless track and special railway track operations, with maximum axle loads of $200 \mathrm{kN}$ and $140 \mathrm{kN}$ for train speeds of $130 \mathrm{~km} / \mathrm{h}$ and $300 \mathrm{~km} / \mathrm{h}$, respectively. Material type B is equivalent to timber sleepers for UIC $5 / 6$ track categories, with a maximum $225 \mathrm{kN}$ axle load for a train speed of $160 \mathrm{~km} / \mathrm{h}$, and material type $\mathrm{C}$ is equivalent to hardwood sleeper for the heavy-haul track with a maximum axle load of $350 \mathrm{kN}$ for a train speed of $80 \mathrm{~km} / \mathrm{h}$.

In Table 1 [36], some mechanical properties of
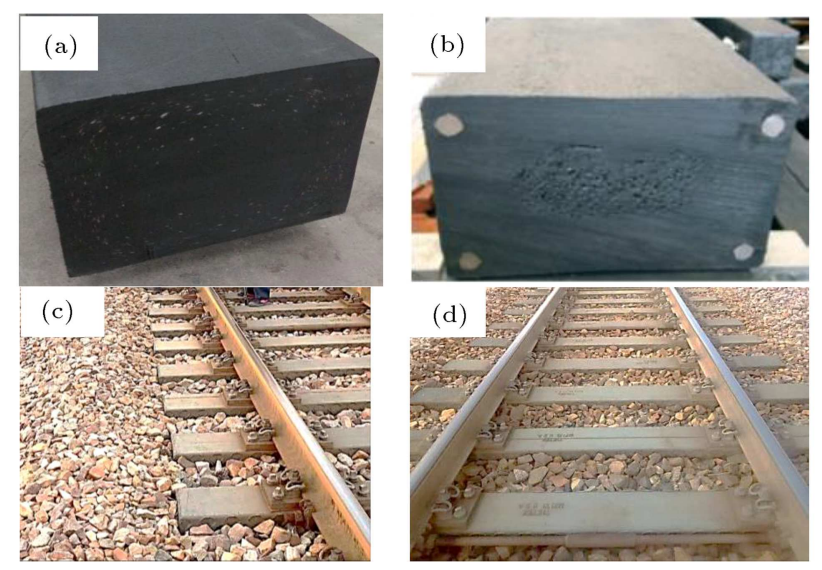

Figure 2. Cross-section of Kunststof Lankhorst Product (KLP) sleepers High-Density Polyethylene (HDPE): (a) Without steel bar, (b) with steel bars, (c), and (d) Tietek sleeper used in China (photo credit: G. Jing). 
Table 1. Mechanical properties of plastic sleepers according to ISO standard [36].

\begin{tabular}{ccccc}
\hline $\begin{array}{c}\text { EN ISO } \\
\text { standard }\end{array}$ & $\begin{array}{c}\text { Bending strength } \\
(\mathbf{M P a})\end{array}$ & $\begin{array}{c}\text { Flexural modulus } \\
(\mathbf{M P a})\end{array}$ & $\begin{array}{c}\text { Shear strength } \\
(\mathbf{M P a})\end{array}$ & $\begin{array}{c}\text { Longitudinal compression } \\
\text { strength }\end{array}$ \\
\hline Type A & $\geq 28$ & $\geq 6000$ & $\geq 7$ & $\geq 40$ \\
Type B & $\geq 18$ & $\geq 2500$ & $\geq 4.5$ & $\geq 8$ \\
Type C & $\geq 13.8$ & $\geq 1170$ & - & - \\
\hline
\end{tabular}

a plastic sleeper for adoption in the industry are presented based on ISO standards. Lampo et al. [37] discussed the requirement to use KLP sleepers as an alternative to timber sleepers in the United States. A bending test was performed on a High-Density Polyethylene (HDPE) sleeper with a $25 \mathrm{~mm}$ steel bar, the results showed that the ultimate strength of the sleeper exceeded $31 \mathrm{MPa}$. In a study done by the Transportation Technology Center [38], the effect of temperature on the railway track vertical stiffness which has plastic sleepers was quantified. The measurement data showed that the vertical track modulus with plastic sleeper was comparable to that with oak-wood sleeper and was not significantly affected by the change of temperature within the range of 57 degrees in the environment and 88 degrees in the center of the sleeper [38]. The Federal Railroad Administration (FRA) [39] conducted a series of tests to address the effects of temperature and fastening systems on the cracking and impact properties of plastic sleepers. It was found that compared to the test performed at ambient and high temperature, during the low-temperature test, the increase of the stiffness of the sleeper was significantly higher. The test results showed that the fastening system could cause a significant reduction of resistance of the sleeper. The mechanical properties of Glass Fiber Reinforced Polymer (GFRP) sleepers made of thermoplastics and continuous glass fibers were studied by Vijay et al. [40]. Fatigue test, nail pull test and field test were carried out in this research. The results showed that the strength and fatigue resistance of these sleepers were similar to those of timber sleepers. The behavior and longterm performance of the entire rail system with HDPE sleepers were studied by Lotfy and Issa [41], using static and cyclic test methods. The results of this study showed the behavior of HDPE sleepers under fatigue loading, normal wear, and minimal degradation.

Considering low fatigue strength, environmental issues resulting in a sharp reduction in forest resources, increasing train axle loads and speeds, timber sleepers may not be an available option for railway tracks construction. As is evident from literature, so far the static and dynamic behavior of the new generation of KLP sleepers with steel bars had not been investigated, while this subject is very important in the areas relating to railway tracks and modeling their behavior. In addition, Finite Element Method (FEM) modeling of KLP sleepers is needed to conduct more research on this new type of sleepers. Therefore, in three bending moment tests in the Mechanical Laboratory of TU Delft, two types of KLP sleepers including HDPE-25 and LDPE-16 have been studied for railway tracks. They were investigated by performing static, dynamic, and longtime flexural tests. Six strain gauges were mounted inside of each of these two sleepers to study the yield behavior of steel bars in the longtime bending moment test. Sensitivity analysis has been performed to check the diameter of other steel bars of HDPE and LDPE to meet the structural and economic optimization requirements of these sleepers. Therefore, HDPE-16 and LDPE-25 are also considered for the further analysis of mechanical behavior.

\section{Material properties of KLP sleepers}

Lankhorst Moldings Sneek-Holland [42] designed two more durable reinforced plastic sleepers, namely HDPE sleeper and LDPE sleeper, with reinforcing steel bar diameters of $25 \mathrm{~mm}$ and $16 \mathrm{~mm}$, respectively. There are some differences between HDPE and LDPE type KLP sleepers. The LDPE has four reinforcement steel bars with a diameter of $16 \mathrm{~mm}$, made of lowdensity polyethylene recycled plastic. The HDPE has four $25 \mathrm{~mm}$ reinforcement steel bars and is made of high-density polyethylene recycled plastic. Given that LDPE has lower price, weight, and mechanical properties, it is recommended to use these two types for railway tracks (Type B). The characteristics of these two types of KLP sleepers are presented in Table 2.

\section{Experimental study}

\subsection{Bending moment test}

One of the criteria for evaluating the sleepers is the maximum bearing loading level which produces the first crack identified by operators using portable microscopes [42]. This method is mostly used for concrete sleepers based on AS1085.14-2009 [43], AREMA 2017 [44], TB/T 1879-2002 [45] and UIC-713R [46]. In this research, a bending test is performed based on the ISO standard for plastic sleepers [36]. Two HDPL/LDPE sleepers are manufactured, and six strain gauges are mounted on the steel bars to study their flex- 
Table 2. Characteristics of Kunststof Lankhorst Product (KLP) sleepers including HDPL/LDPE.

\begin{tabular}{|c|c|c|c|c|c|}
\hline \multirow[b]{2}{*}{ Sleeper type } & \multicolumn{3}{|c|}{ Steel bars } & \multirow[b]{2}{*}{$\begin{array}{l}\text { Dimension } \\
\qquad(\mathrm{mm})\end{array}$} & \multirow{2}{*}{$\begin{array}{c}\text { Bending } \\
\text { modulus } \\
(\mathrm{MPa})\end{array}$} \\
\hline & $\begin{array}{c}\text { Diameter } \\
(\mathrm{mm})\end{array}$ & Type & $\begin{array}{l}\text { Min. plastic } \\
\text { cover }(\mathrm{mm})\end{array}$ & & \\
\hline HDPE & 25 & \multirow{2}{*}{$\mathrm{S} 235$} & 15 & \multirow{2}{*}{$250 * 150 * 2500$} & $650-1250$ \\
\hline LDPE & 16 & & 12 & & $250-400$ \\
\hline
\end{tabular}

ural strength properties [47]. Both KLP sleepers have undergone static, dynamic, and long-term static 3point bending tests. During the tests, a metal rod is installed as the reference of zero point, and the deflection is measured by the displacement of the center of the beam relative to the reference rod using a displacement sensor of the Linear Variable Differential Transformer (LVDT) as can be seen in Figure 3. The actuator is loaded in the center of the sleeper, about $1250 \mathrm{~mm}$ from the end, and the sleeper rested on two supports that were nearly $1500 \mathrm{~mm}$ apart from each other.

Figure 4 shows that the six strain gauges are mounted at $400 \mathrm{~mm}$ (1/6 sleeper length), $900 \mathrm{~mm}(1 / 3$ sleeper length), and $1250 \mathrm{~mm}$ (the sleeper center) from the left side of the sleeper on the steel bars at the top and bottom of sleeper. The strain gauges were connected to a data logger through wires, as shown in Figure 4. The strain gauges are produced by TML and are suitable for steel, and the data logger is TMR produced by TML.

\subsubsection{Static bending moment test}

Three static 3 -point bending tests were performed on both H/LDPE sleepers with different loading speeds. The sleeper was loaded with a preload of $2 \mathrm{kN}$, and then the load was increased at three speeds of $0.5 \mathrm{kN} / \mathrm{s}$, $1 \mathrm{kN} / \mathrm{s}$, and $2 \mathrm{kN} / \mathrm{s}$. The load reached its maximum value when the sleeper failed and then decreased to the $2 \mathrm{kN}$ loading level at the same loading speed. Then the maximum load of H/LDPE is used in Eq. (1) to calculate flexural strength $(\mathrm{MPa})$ of sleepers $\left(\sigma_{f}\right)$ and compare it with ISO standard (Table 1). Eq. (1) can be expressed as follows:

$$
\sigma_{f}=\frac{3 F L}{2 b h^{2}}
$$

where $F, L, b$, and $h$ represent maximum applied load
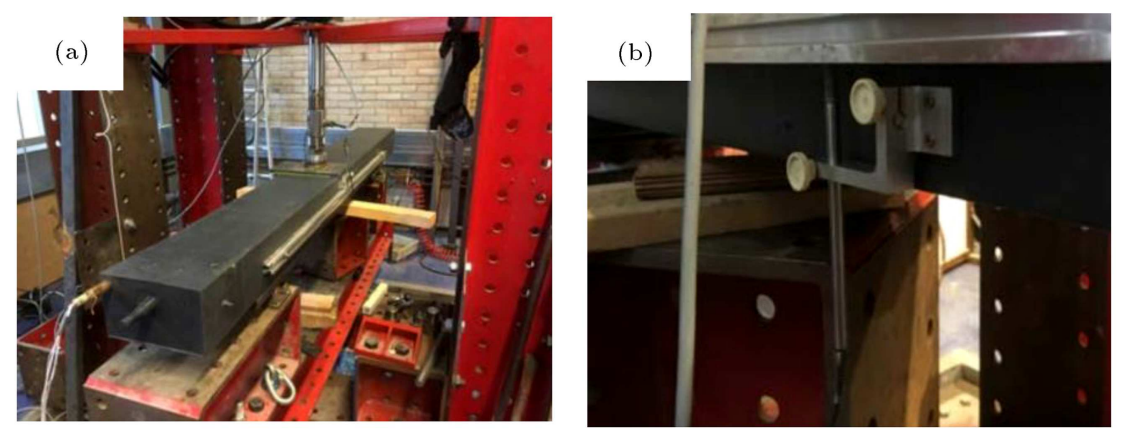

Figure 3. An overview of experimental test including: (a) Placement of sleeper and (b) Linear Variable Differential Transformer (LVDT) location.

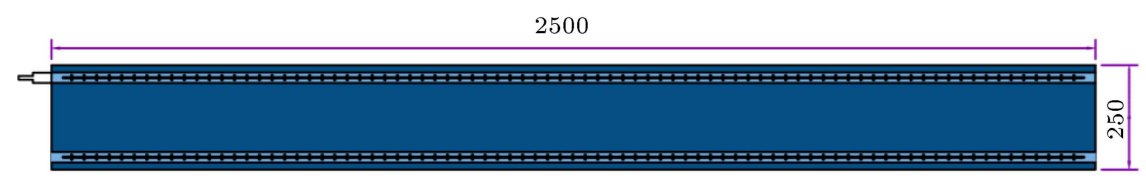

(a)

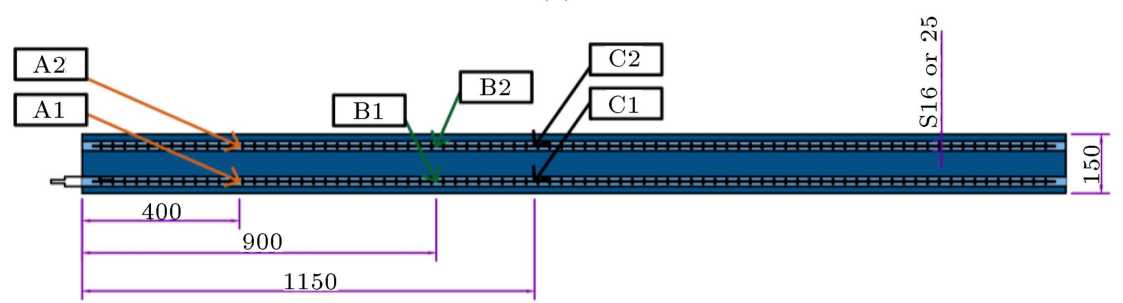

(b)

Figure 4. Location of strain gauges in sleepers body and unit $(\mathrm{cm})$. 


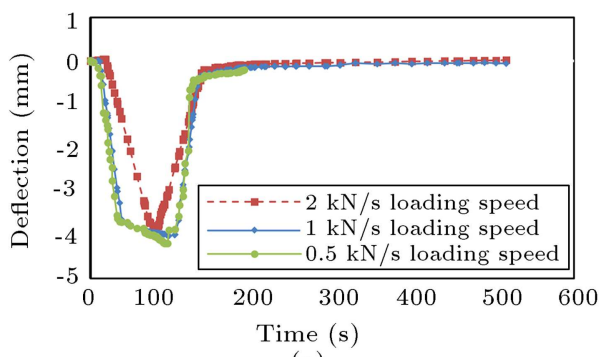

(a)

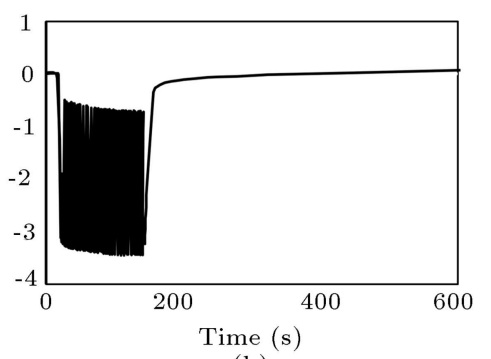

(b)

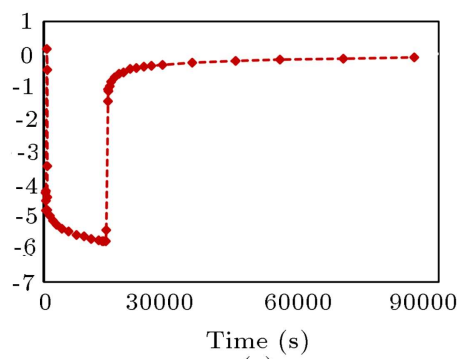

(c)

Figure 5. (a) Static, (b) dynamic, and (c) longtime static bending tests of HDPE-25.

(N), span of supports (mm), sleeper width (mm), and sleeper height $(\mathrm{mm})$, respectively.

\subsubsection{Dynamic bending moment test}

The dynamic 3-point bending tests were carried out on both H/LDPE sleepers. The dynamic loading had a cyclic load between $3 \mathrm{kN}$ and $30 \mathrm{kN}$ which was applied to the sleeper at a frequency of $5 \mathrm{~Hz}$.

\subsubsection{Longtime static bending moment test}

A longtime static test was also performed on both $\mathrm{H} / \mathrm{LDPE}$ sleepers. A load of $30 \mathrm{kN}$ was applied for 4 hours. After 4 hours, the entire load was completely unloaded, and then the measurement continued for 12 hours This measurement was recorded with a sampling frequency of $0.1 \mathrm{~Hz}$.

\subsubsection{Results and discussion}

As shown in Figure 5(a) the minimum speed of loading had a maximum deflection of $4.2 \mathrm{~mm}$. Also, it can be seen that after unloading, the deflection of HDPE25 returned to its original position. However, a little amount of deflection remained in middle of HDPE-25 as about $0.3 \mathrm{~mm}$. In Figure $5(\mathrm{~b})$, the $5 \mathrm{~Hz}$ cyclic load was applied in a 3 -point bending test to the HDPE25. From $3.2 \mathrm{~mm}$ at the beginning of the first cycle to $3.5 \mathrm{~mm}$ at the last cycle of loading, a slight increase in deflection can be seen. It can be seen that the deflection of the sleeper returned to the first position with slight plastic deformation of $0.1 \mathrm{~mm}$. Figure $5(\mathrm{c})$ shows the results of the 4-hour static 3 -point bending moment test of the HDPE-25. The deflection value of the longtime test is considerably greater than those of the static and dynamic tests. The plastic deformation value after unloading was also higher at $0.5 \mathrm{~mm}$, which indicates that the strength against fatigue loads was lower compared to the previous static and dynamic tests. As shown in Figure 6, the strains of the HDPE25 can be seen during the 4-hour static 3-point bending moment test. This shows that strain gauges mounted closer to the loading zone of the sleeper measured more strains. C1 strain gauge detected the maximum strain value of $1000 \mu \mathrm{e}$, which is followed by B1 with $600 \mu \mathrm{e}$. These strain gauges were located at the bottom of the loaded part of the sleeper where steel bars were under

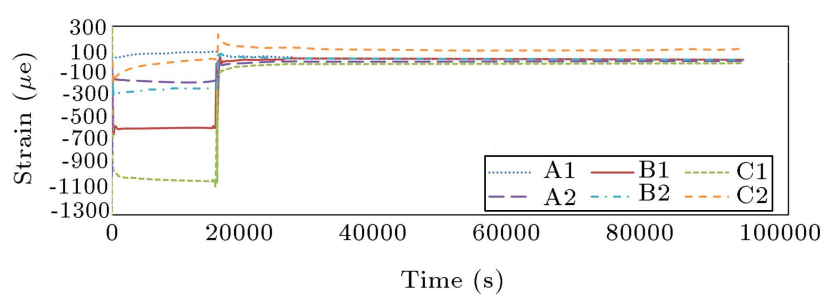

Figure 6. Strains of longtime static 3 -point bending test for HDPE-25.

significant tensile stresses. Other strain gauges did not experience high tensile or compressive stresses due to the high resistance of the sleeper against the $30 \mathrm{kN}$ loading level.

Figure $7(\mathrm{a})$ shows the results of the static 3-point bending moment test of the LDPE-16. As expected, the lower loading speed $(0.5 \mathrm{kN} / \mathrm{s}$ loading speed $)$ resulted in a higher deflection of $8.7 \mathrm{~mm}$. Figure $7(\mathrm{~b})$ shows the $5 \mathrm{~Hz}$ dynamic 3 -point bending moment test of the LDPE-16. As the cyclic loading time increased, the deflection of sleeper increased slightly, from $6.8 \mathrm{~mm}$ in the first cycle to $7.2 \mathrm{~mm}$ in the last cycle. Figure 7 (c) shows the 4-hour static 3 -point bending moment test of the LDPE-16 sleeper. Compared with HDPE-25 and the other two static and dynamic tests, it showed greater deflection, which means that the sleeper had a lower strength against fatigue loads.

As shown in Figure 8, the strains can be seen during the 4-hour static 3-point bending moment test of the LDPE-16. The strain gauge $\mathrm{C} 1$, which was under force, showed a larger strain compared to other gauges. There was a peak in the strain of $\mathrm{C} 1$ from $-2000 \mu \mathrm{e}$ to $-2500 \mu \mathrm{e}$; it shows that the steel bar yields due to the $30 \mathrm{kN}$ load applied for around three and half hours.

After calculating the flexural strength of the two types of HDPE-25 and LDPE-16, they were found to be $28 \mathrm{MPa}$ and $20 \mathrm{MPa}$, respectively. Therefore, both HDPE-25 and LDPE-16 can be used based on standards $(\geq 18 \mathrm{MPa})$; however, considering longtime static test, LDPE-16 failed and cannot be used. When the LDPE-16 was loaded with $30 \mathrm{kN}$ for a long time (4hour), the reinforcing steel bar yielded, therefore, the LDPE-16 did not meet the standard requirement. The comparison of the flexural strength of KLP sleepers and 


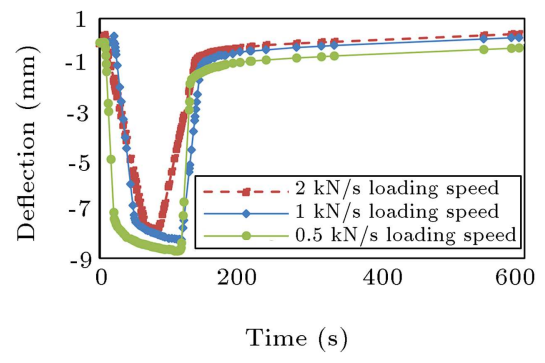

(a)

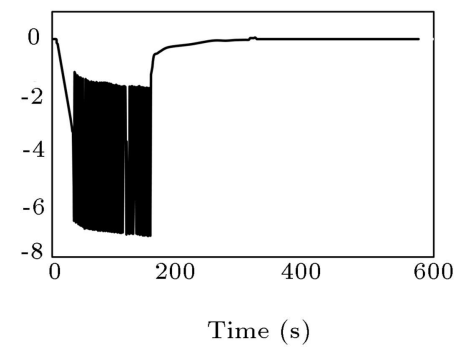

(b)

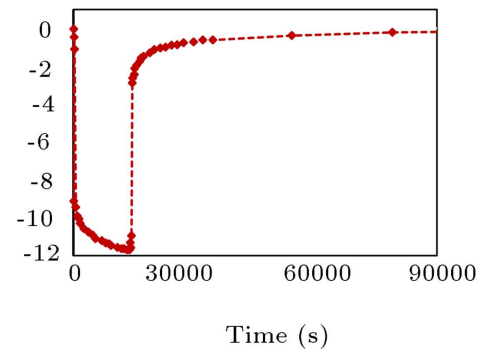

(c)

Figure 7. (a) Static, (b) dynamic, and (c) longtime static bending tests of LDPE-16.

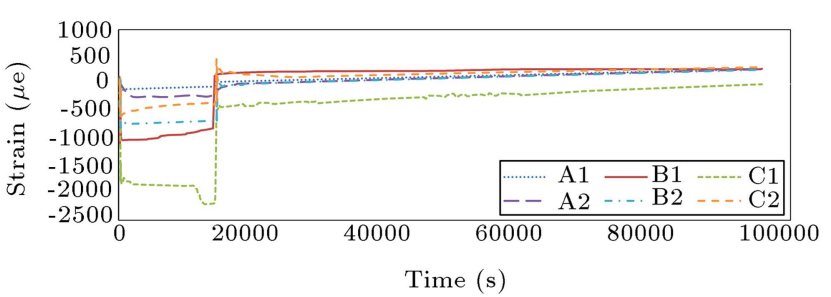

Figure 8. Strains of longtime static 3-point bending test for LDPE-16.

timber sleepers showed that the hardwood-oak sleepers had a moderate bending strength of $41 \mathrm{kN}$ [22], which means that it was almost $40 \%$ lower than HDPE- 25 and $15 \%$ higher than LDPE- 16 .

\subsection{Impact hammer test}

The impact hammer test is performed on HDPE-25 as the most commonly used plastic sleeper to show the natural frequencies of the sleeper and validate the numerical modeling results of the frequency analysis. This sleeper has been chosen because it can pass all mechanical tests. Through performing the impact hammer test and using ten accelerometers which were installed on the HDPE-25 at a distance of $275 \mathrm{~mm}$ from each other, the natural frequencies are obtained [48]. The natural frequencies of sleepers are important for the development of a real dynamic model of railway tracks and sleeper itself, which can predict its dynamic responses. Impact hammer test is one of the popular methods for doing modal analysis of structures [4951]. For preparing the free-free condition, the sleeper was placed on two wooden blocks at both ends. The impacts were applied in three places, as can be seen in Figure 9. Impacts are applied five times at each location, to prevent errors in the measurement. The results were incorporated in the Matlab program [52]. Using Fast Fourier Transformer (FFT), the accelerations were converted to the frequency domain to obtain dominant frequencies of HDPE-25 [29].

The calculation of dominant frequencies HDPE25 is shown in Figure 10. The results showed that the first, second, and third natural frequencies of HDPE-25 were close to $37.5 \mathrm{~Hz}, 156.3 \mathrm{~Hz}$ and $237.5 \mathrm{~Hz}$, respectively. These results are used for the validation of frequency analysis in FEM sensitivity analysis. As shown

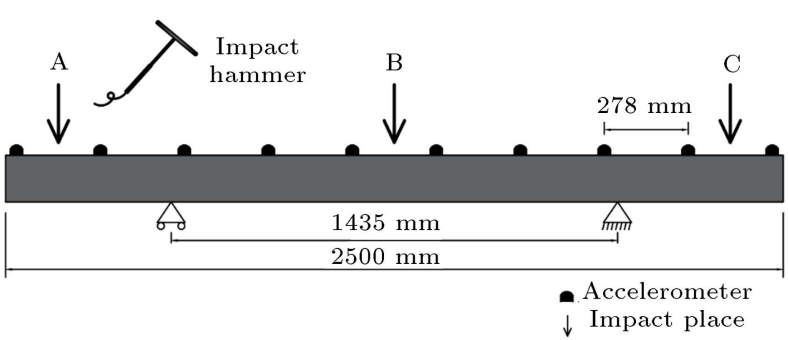

Figure 9. Configuration of sensors and impacts on the HDPE-25 sleeper.

in Figure 10, the dominant frequencies of timber and HDPE sleeper are calculated. It is concluded that the first dominant frequency of HDPE-25 as $37.5 \mathrm{~Hz}$ has an almost $35 \%$ difference compared to that of timber as $57.2 \mathrm{~Hz}$. It is worthy of consideration that the amplitude of timber sleeper frequencies was about ten times that of HDPE which shows the better performance of HDPE sleeper in damping of vibrations. According to the results of modal analysis, the damping ratio of KLP sleepers was 0.34 , which was nearly $8 \%$ higher than the damping ratio of timber sleepers of 0.31 .

\section{Sensitivity analysis}

\subsection{FEM model development}

To analysis the behavior of H/LDPE sleepers, numerical modeling is developed. The steel bars configurations can be seen in Figure 11 . There were four steel bars at the four corners of the sleepers. The Hex mesh was chosen for the discretization of each instance. The mesh size of steel bars and sleepers was $50 \mathrm{~cm}$ and $10 \mathrm{~cm}$, respectively. A mesh size analysis was performed to check the finer mesh sizes of the final results. A static load with a loading rate of 2 $\mathrm{kN} / \mathrm{s}$ is applied to the sleepers at the middle point. For boundary conditions, sleepers rested as simply supported beams. This section aims to categorize the application of four sleepers including HDPE-25, LDPE16, HDPE-16, and LDPE-25 based on the numerical study.

\subsection{Model validation}

To validate the numerical model through experiment, a 


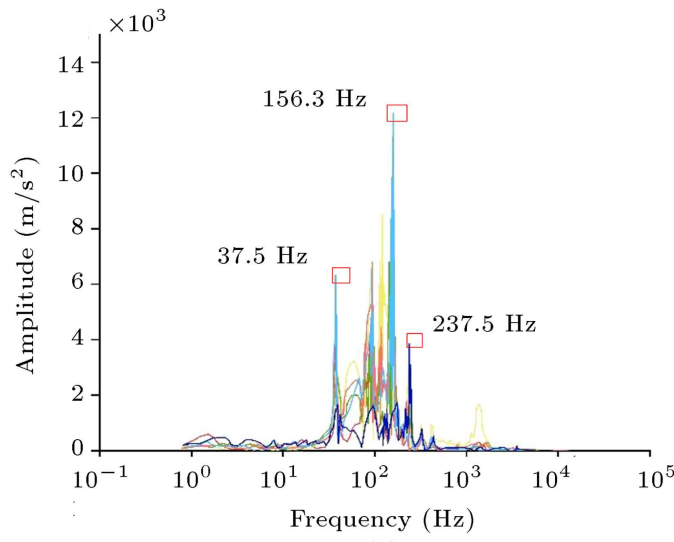

(a)

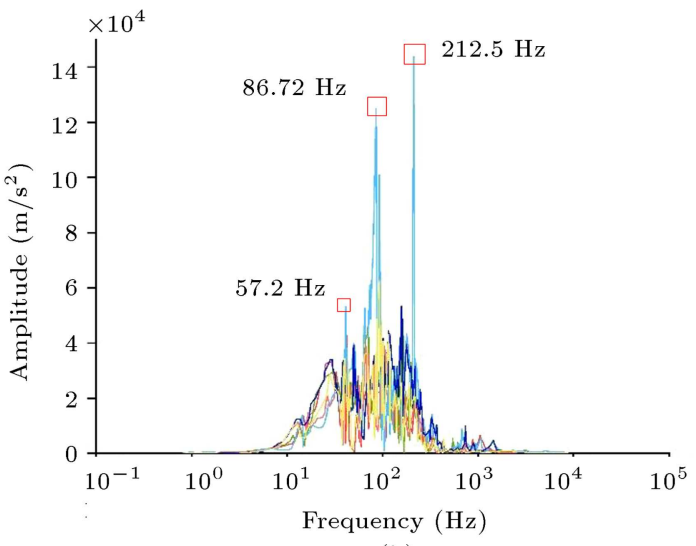

(b)

Figure 10. Dominant frequencies of (a) HDPE-25 and (b) timber sleeper in free vibration analysis.

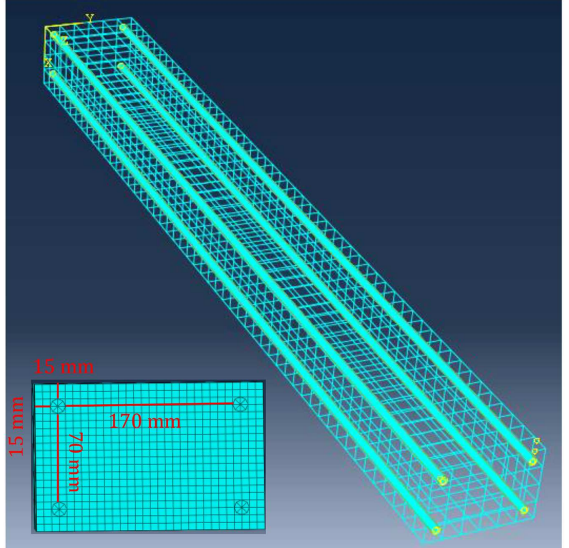

(a)

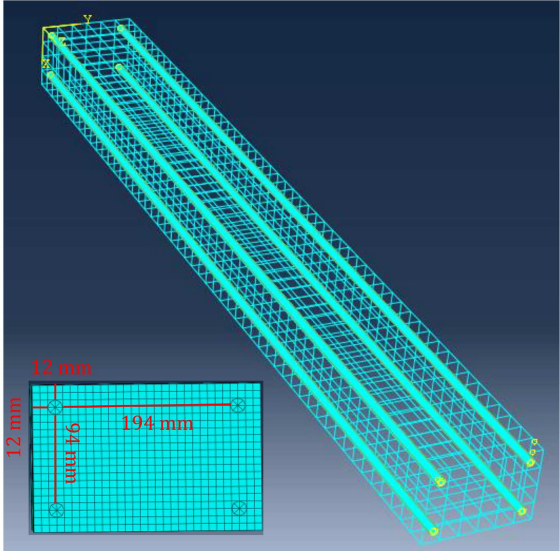

(b)

Figure 11. Steel bars configuration for Kunststof Lankhorst Product (KLP) sleepers: (a) H/LDPE-25 and (b) L/HDPE-16.

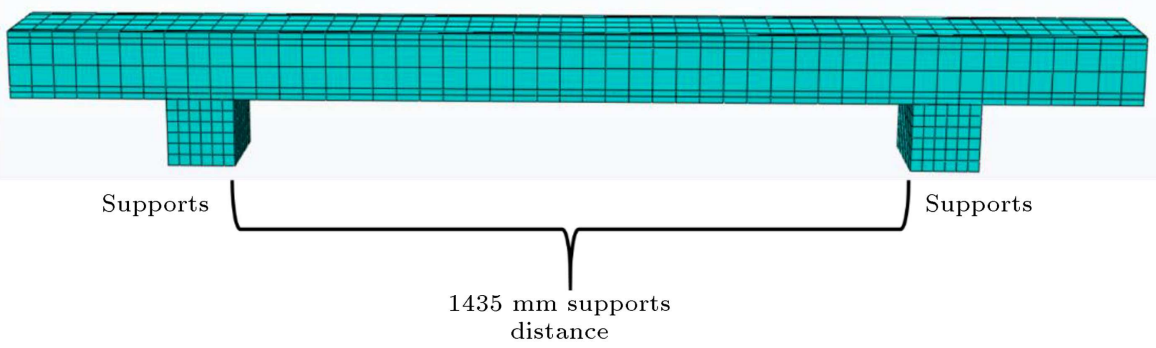

Figure 12. An overview of three bending moment tests of Kunststof Lankhorst Product (KLP) sleepers.

static bending test is considered as shown in Figure 12. In the experimental study, the loading rate of the numerical model and the loading speed of $2 \mathrm{kN} / \mathrm{s}$ were selected. It can be seen from Figure 13 that the deflections of the H/LDPE sleepers in the numerical simulation were almost the same as the maximum deflection obtained through the experimental results. The difference between the maximum deflection of HDPE and LDPE between numerical modeling and experimental effort was $4 \%$ and $2 \%$, respectively.

\subsection{Natural frequencies of KLP sleepers}

To plot the mode shapes of the sleeper and compare them with the experimental results, modal analysis is developed using numerical modeling. It can be seen from Table 3 that the frequencies of the numerical model of HDPE-25 were almost the same as the first, second, and third natural frequencies obtained through the experiment. This can be taken as a shred of strong evidence ensuring the validity of HDPE- 25 vibrational properties in the numerical model. A further frequency 
Table 3. Natural frequencies and mode shapes of four different Kunststof Lankhorst Product (KLP) sleepers.

\begin{tabular}{|c|c|c|c|c|c|}
\hline \multirow{2}{*}{ Mode shape no. } & \multicolumn{4}{|c|}{ Natural frequencies $(\mathrm{Hz})$} & \multirow{2}{*}{ Mode shapes } \\
\hline & HDPE-25 & LDPE-16 & HDPE-16 & LDPE-25 & \\
\hline 1st bending mode shape & 37 & 24 & 28.5 & 31 & \\
\hline 2nd bending mode shape & 155.8 & 122.14 & 150.19 & 125.67 & \\
\hline 3rd bending mode shape & 236 & 193.42 & 234.74 & 196.92 & \\
\hline 4th bending mode shape & 366 & 323 & 353 & 335 & \\
\hline 5th bending mode shape & 469 & 426 & 451 & 441 & \\
\hline 1st torsion mode shape & 60.23 & 44.4 & 61 & 40.31 & \\
\hline
\end{tabular}

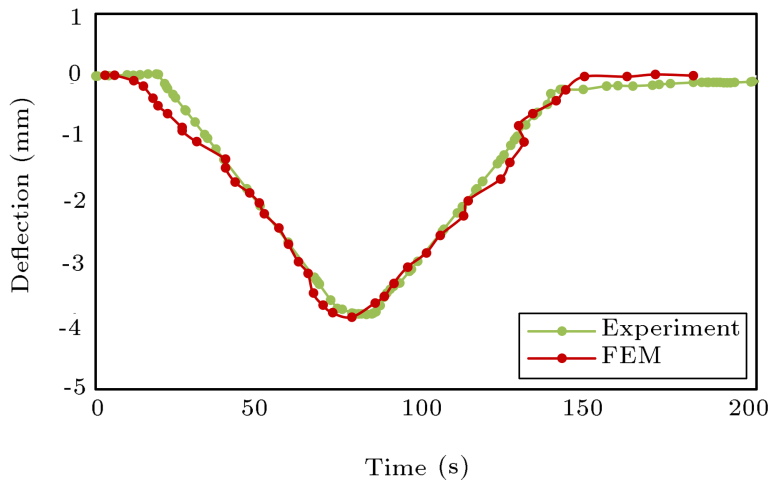

(a)

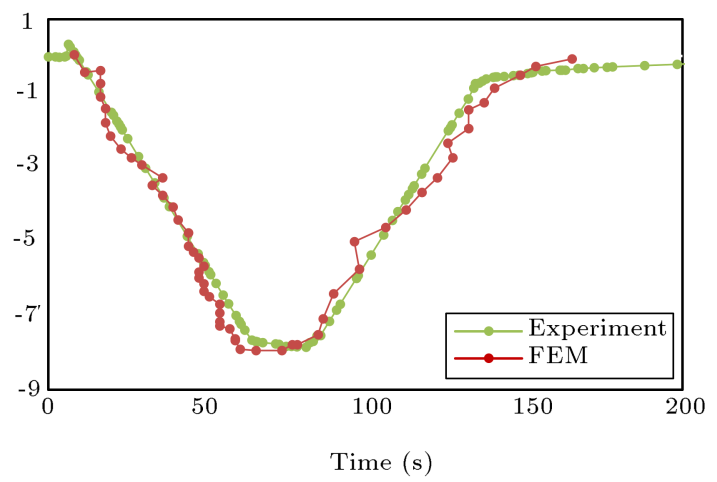

(b)

Figure 13. Validation of Finite Element Method (FEM) results with bending moment test of sleepers: (a) HDPE and (b) LDPE. 
analysis was performed to compare the natural frequencies of H/LDPE-25 and L/HDPE-16. The results show that in the first bending mode shape that the steel bar is directly engaged in deforming, the higher diameter of the steel bar shows higher natural frequencies as the highest belongs to HDPE-25 as $37 \mathrm{~Hz}$, which is followed by $31 \mathrm{~Hz}, 28.5 \mathrm{~Hz}$, and $24 \mathrm{~Hz}$ of LDPE-25, HDPE-16 and LDPE-16, respectively. From the second to fifth mode shapes, higher frequencies also belong to HDPE-25 and 16. In the torsional mode, only the material type was effective for the performance of the sleepers, because these sleepers did not have stirrups for restraining the steel bars. As can be seen, HDPE25 and 16 had higher frequencies than LDPE-16 and 25 due to higher mechanical properties. Considering the actuation frequencies of railway track due to dynamic loads which are mostly in the range of $200 \mathrm{~Hz}$ to $300 \mathrm{~Hz}[3,53]$, it is better that the sleeper's frequency be kept out of this frequency range to avoid track resonance. Therefore, HDPE-25 shows the closest, and LDPE-16 shows the furthest frequencies from this frequency range compared with other KLP sleepers.

\subsection{Maximum stresses of KLP sleepers}

ISO standard [36] provides guidelines for calculating reference test loads for plastic sleeper types. A three bending moment test is simulated, and the results are reported in the following sections. A static load with a loading speed rate of $2 \mathrm{kN} / \mathrm{s}$ is applied to the sleepers, and the corresponding stresses are presented. Table 4 shows the material properties used in the model. The sleeper is modeled as a simply supported beam with a distance of $1500 \mathrm{~mm}$ between the supports.

The validated models based on the maximum deflection of sleepers are used for presenting the corresponding stresses of $\mathrm{H} / \mathrm{LDPE}$ sleepers. As shown in Figure 14, the maximum stresses of both H/LDPE sleepers appeared on steel bars, which means that the maximum stress is transferred to the steel bars, resulting in less stress on the composite.

As is clear from Figure 15, the maximum stress in the HDPE-25 and LDPE-25 steel bars were $0.13 \mathrm{GPa}$ and $0.19 \mathrm{GPa}$, respectively, with almost $30 \%$ difference; while the corresponding stresses in the composite were around $5.22 \mathrm{MPa}$ and $5.3 \mathrm{MPa}$ with almost $1 \%$ difference. This difference shows that the identical steel bars banned stresses to be transferred to composite, while LDPE-25 steel bars underwent higher stresses. For HDPE-16 and LDPE-16, the maximum stresses transferred to the composites were about $4 \mathrm{MPa}$ and $3.3 \mathrm{MPa}$, respectively, expressing a difference of about $17 \%$, while the maximum stresses transferred to the steel bars were $0.2 \mathrm{GPa}$ and $0.15 \mathrm{GPa}$, respectively, expressing a difference of nearly $25 \%$. Due to the smaller diameter and resistance of the $16 \mathrm{~mm}$ steel bar, a certain degree of stress is transferred to the composite material, which could fail under high load and long-term use.

Figure 16 shows the yield zone of steel bars for each sleeper. HDPE-25 had higher flexural strength, about $68 \mathrm{kN}$, which shows that the design is relatively overdesigned and is not economically acceptable. The flexural strength of LDPE-16 was lower than that of its counterparts which was $35 \mathrm{kN}$. Two other new designs (HDPE-16 and LDPE-25) based on sensitivity analysis studies showed flexural strengths of $33 \mathrm{kN}$ and $63 \mathrm{kN}$, respectively. Therefore, it can be concluded that LDPE-25 can be a substitution for HDPE-25 in railway tracks with lower weight and price but almost the same flexural strength.

\subsection{Bending modulus calculation}

The bending modulus represents the ratio of stress to the corresponding strain of the material within the elastic region. Stiff materials demonstrate a high modulus and ductile materials exhibit a low modulus. In this study bending modulus for all four designed sleepers were calculated using FEM results and Eq. (2) based on ASTM D790 standard [54]. Figure 17 shows the bending modulus values of HDPE-25/16 and LDPE-25/16.

$$
E=\frac{L^{3} F}{4 w h^{3} d}
$$

where $w, h, L, d$, and $F$ represent the width and height of the sleeper, the distance between the two outer supports, and the deflection and the load applied at the middle of the sleeper.

The maximum bending modulus of HDPE-25 was almost $0.6 \mathrm{MPa}$, followed by HDPE-16, LDPE-25, and LDPE-16, which had maximum bending modulus values of $0.32 \mathrm{MPa}, 0.3 \mathrm{MPa}$, and $0.2 \mathrm{MPa}$, respectively. The bending modulus HDPE-25 was almost $42 \%, 45 \%$,

Table 4. Material properties of H/LDPE sleepers used in Finite Element Method (FEM) modeling of bending moment test.

\begin{tabular}{|c|c|c|c|c|c|}
\hline Sleeper pr & perties & $\begin{array}{l}\text { Density } \\
\left(\mathrm{kg} / \mathbf{m}^{3}\right)\end{array}$ & $\begin{array}{c}\text { Elastic modulus } \\
(\mathrm{MPa})\end{array}$ & Poisson's ratio & $\begin{array}{c}\text { Plasticity modulus } \\
\text { (MPa) }\end{array}$ \\
\hline \multirow{2}{*}{ Composite } & HDPE & 870 & 800 & 0.4 & \multirow{2}{*}{-} \\
\hline & LDPE & 870 & 325 & 0.4 & \\
\hline \multicolumn{2}{|c|}{ Steel bars } & 7850 & 210000 & 0.3 & 235 \\
\hline
\end{tabular}



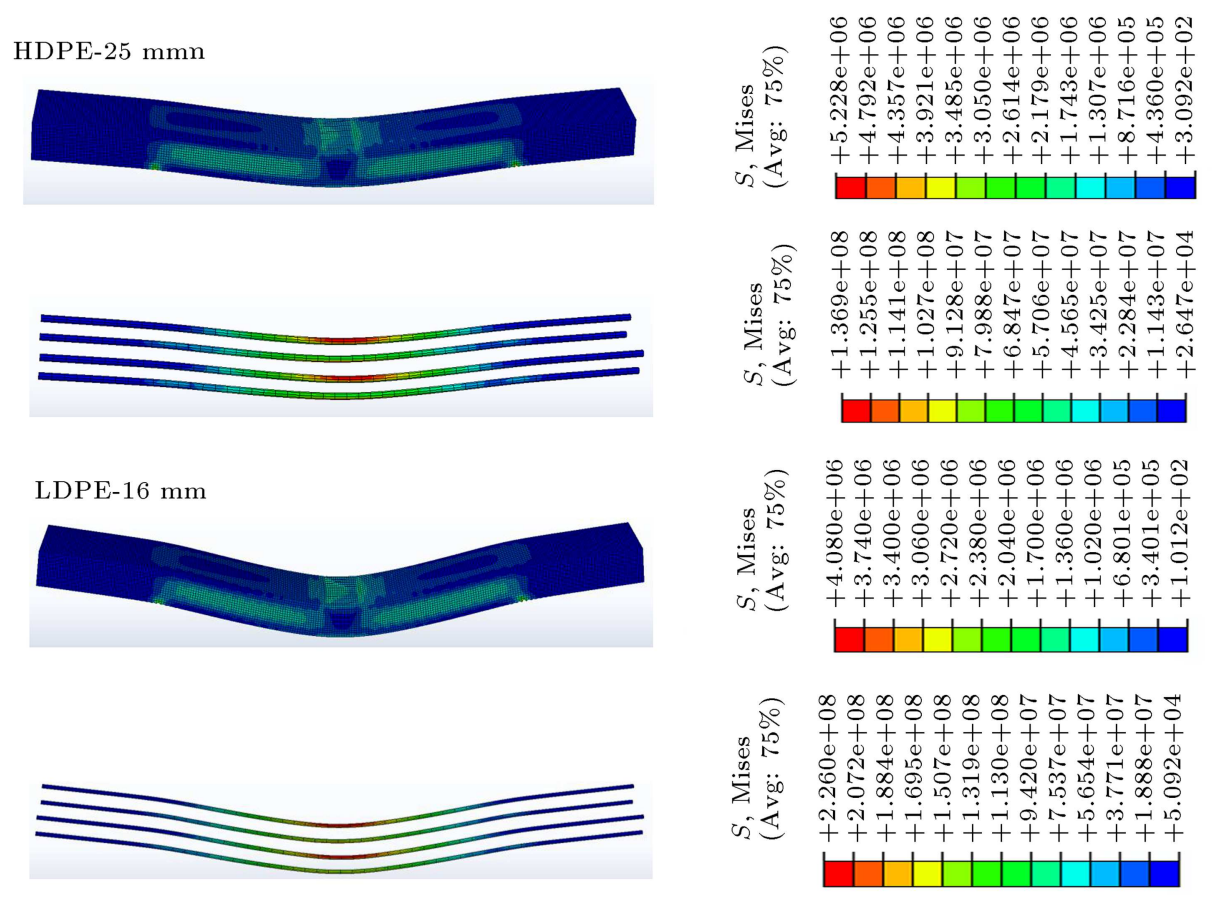

HDPE-16 mm
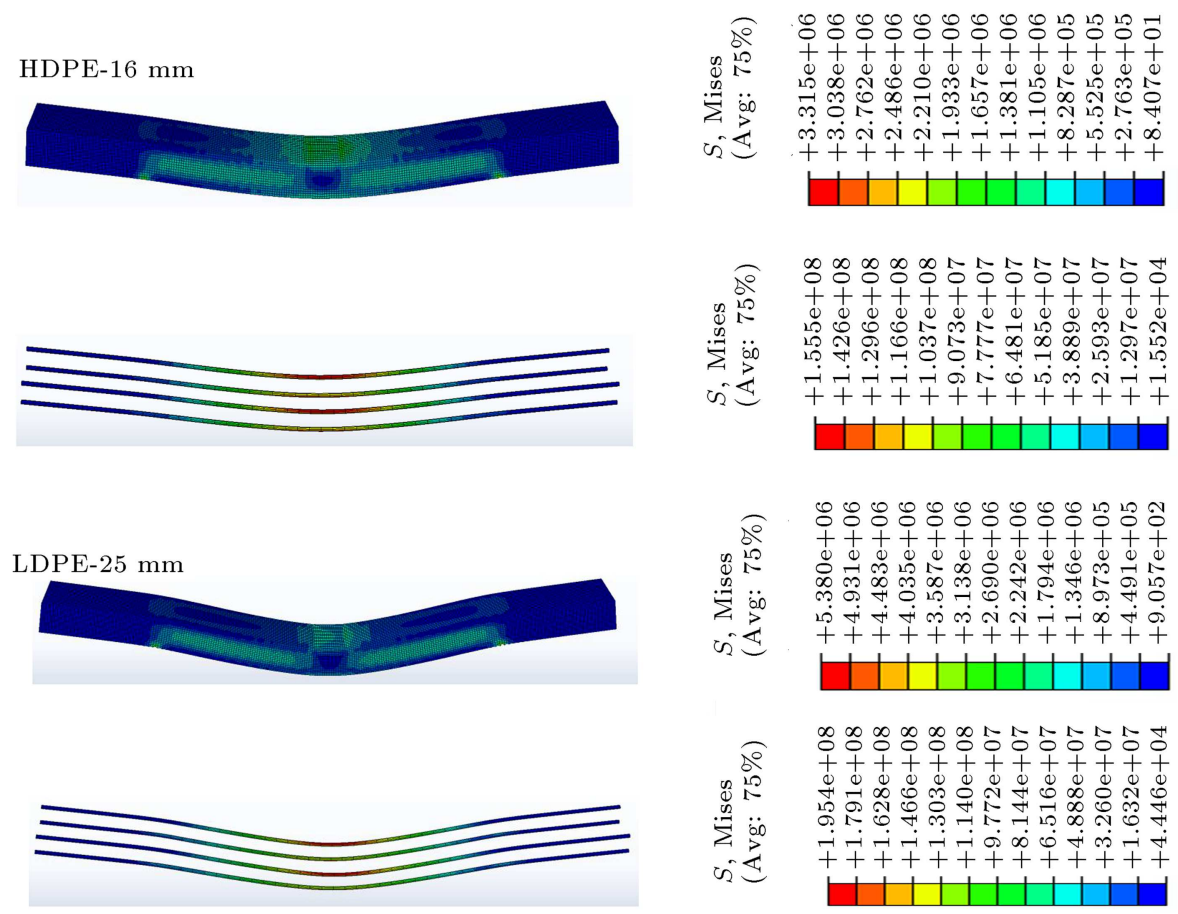

Figure 14. Stress distribution $(\mathrm{Pa})$ of the center bending test of sleepers and steel bars for HDPE-25; LDPE-16; HDPE-16; and LDPE-25.

and $65 \%$ higher than HDPE-16, LDPE-25 and, LDPE16 , respectively.

\section{Conclusions}

Increasing axle loads and train speeds have motivated researchers and track owners to consider designing new types of sleepers. Recently, several composite sleepers have been developed worldwide; however, new types such as Kunststof Lankhorst Product (KLP) sleepers have emerged. Especially with the development of railway tracks using timber sleepers, the track components will be subject to greater dynamic impacts, thereby accelerating degradation and shortening the service life. Considering the limitations of the use of timber sleepers, it has become crucial to produce a new 


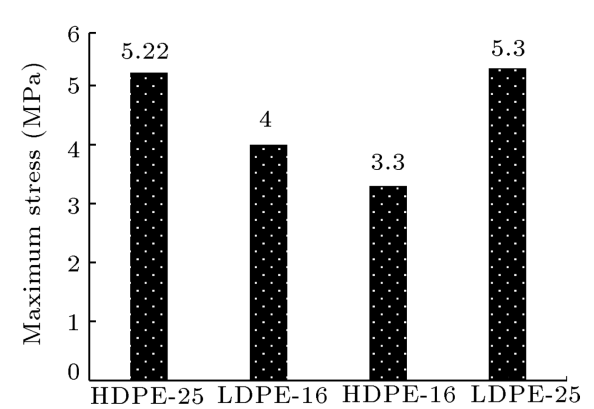

(a)

Figure 15. (a) Maximum stress of KLP sleepers in composite. (KLP) sleepers in steel bars.

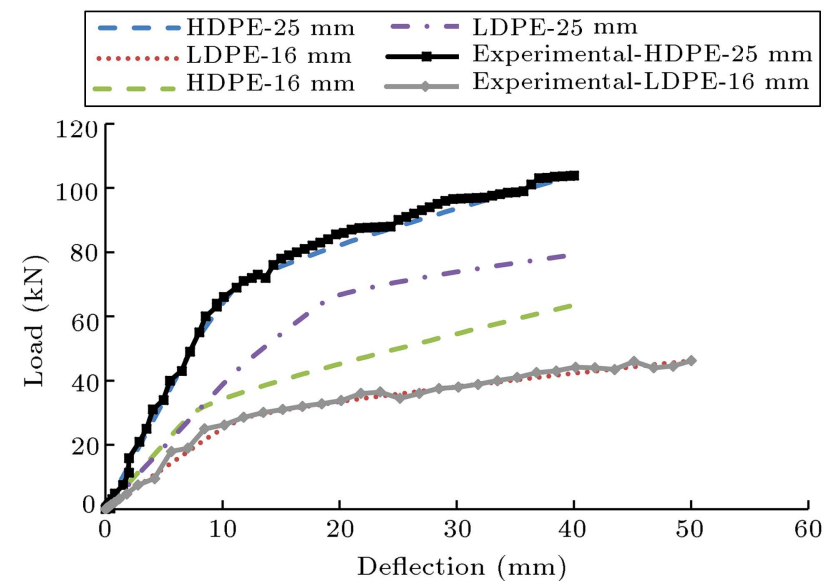

Figure 16. Load-center displacement relationship for Kunststof Lankhorst Product (KLP) sleepers.

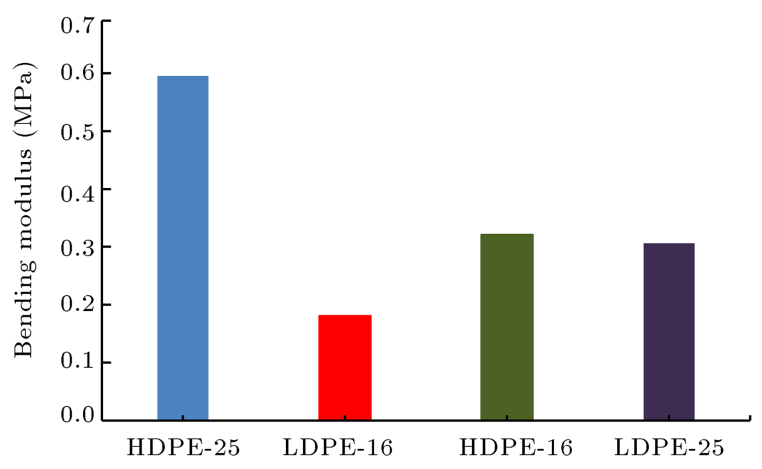

Figure 17. Bending modulus values based on Finite Element Method (FEM) results for HDPE-25\&16 and LDPE-25\&16 sleepers.

generation of KLP sleepers equipped with steel bars that provide greater damping and higher mechanical properties. In this study, the mechanical behavior of HDPE-25 and LDPE-16 as two current KLP sleepers were studied and numerical modeling is accordingly developed to analyze the behavior of HDPE-16 and LDPE-25. The findings of the current study can be summarized as follows:

1. HDPE-25 and LDPE-16 sleepers showed poor bending resistance to long-term static loading under

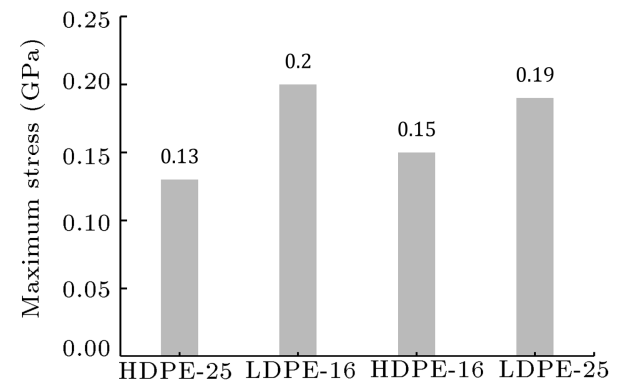

(b)

(b) Maximum stress of Kunststof Lankhorst Product a 4-hour load of $30 \mathrm{kN}$, and their deflection was relatively large, about $5.75 \mathrm{~mm}$ and $11.7 \mathrm{~mm}$, respectively. Strain results of steel bars in the middle of sleeper under bending load showed that the steel bars of LDPE-16 yielded under $30 \mathrm{kN}$ load in a longtime static test;

2. The natural frequencies of HDPE-25 were $37 \mathrm{~Hz}$, $155.8 \mathrm{~Hz}, 236 \mathrm{~Hz}$, and $60.23 \mathrm{~Hz}$. As is evident from these findings, the HDPE-25 natural frequencies were higher than those of its counterparts. The conventional actuation frequencies of the train wheels are in the range of $200 \mathrm{~Hz}$ to $300 \mathrm{~Hz}$, while in the present study, it is observed that the natural frequencies of LDPE-25 were $31 \mathrm{~Hz}, 125.67 \mathrm{~Hz}$, $169.92 \mathrm{~Hz}$, and $40.31 \mathrm{~Hz}$. These findings reveal the significant difference between the conventional actuation frequencies of the train wheels and the natural frequencies of LDPE-25;

3. According to numerical bending test results, HDPE-25 had higher flexural strength around $68 \mathrm{kN}$. The flexural strength of LDPE-16 $(35 \mathrm{kN})$ was lower than other flexural strengths. Two other new designs of HDPE-16 and LDPE-25 based on the sensitivity analysis study showed flexural strengths of $33 \mathrm{kN}$ and $63 \mathrm{kN}$, respectively. Therefore, replacing HDPE-25 with LDPE-25 can be cost-effective and ensure more efficiency in terms of weight, while it can provide the same degree of flexural strength as provided through using its counterpart;

4. The maximum stresses of HDPE-25 and LDPE25 steel bars were $0.13 \mathrm{GPa}$ and $0.19 \mathrm{GPa}$, respectively, with a difference of nearly $30 \%$; while the corresponding stresses in the composite were about 5.22 $\mathrm{MPa}$ and $5.3 \mathrm{MPa}$, with a difference of nearly $1 \%$. This difference indicates that the same steel bars banned stresses to be transferred to composite materials, but LDPE-25 steel bars must withstand higher stresses. For HDPE-16 and LDPE-16, the maximum stresses in composites were around $4 \mathrm{MPa}$ and $3.3 \mathrm{MPa}$, respectively, showing a difference of about $17 \%$, while in the 
steel bars, the stresses were $0.2 \mathrm{GPa}$ and $0.15 \mathrm{GPa}$, showing a difference of nearly $25 \%$. Due to the lower diameter and resistance of $16 \mathrm{~mm}$ steel bars, a certain degree of stress is transferred to the composite, therefore the steel bars with $16 \mathrm{~mm}$ diameter are not suitable for KLP sleepers for Type B railway tracks;

5. HDPE-25 had maximum bending modulus with almost 0.6 MPa followed by HDPE-16, LDPE-25, and LDPE-16 with maximum bending modulus values of $0.32 \mathrm{MPa}, 0.3 \mathrm{MPa}$, and $0.2 \mathrm{MPa}$, respectively. The bending modulus HDPE- 25 was almost $42 \%, 45 \%$, and $65 \%$ higher than that of HDPE- 16 , LDPE-25, and LDPE-16, respectively.

\section{Acknowledgment}

This paper has been supported by the China Academy of Railway Science Foundation (Grant No. 2018YJ043). The authors would like to thank Lankhorst for providing test samples and financial supports.

\section{References}

1. Esmaeili, M., Zakeri, J.A., Kaveh, A., Bakhtiary, A., and Khayatazad, M. "Designing granular layers for railway tracks using ray optimization algorithm", Sci. Iran., 22(1), pp. 47-58 (2015).

2. Zakeri, J.A. and Hassanrezaei, H. "Experimental investigation on effect of winged sleeper on lateral resistance of ballasted track", Sci. Iran., A, 28(2), pp. 656-665 (2021).

3. Jing, G., Wang, J., Wang, H., and Siahkouhi, M. "Numerical investigation of the behavior of stone ballast mixed by steel slag in ballasted railway track", Constr. Build. Mater., 262, p. 120015 (2020).

4. Zhao, J., Chan, A.H.C., and Burrow, M.P.N. "Reliability analysis and maintenance decision for railway sleepers using track condition information", J. Oper. Res. Soc., 58(8), pp. 1047-1055 (2007).

5. Sadeghi, J. "Field investigation on vibration behavior of railway track systems", International Journal of Civil Engineering, 8, pp. 232-241 (2010).

6. Hill, K. and Relph, S., Corus UK Ltd, Steel railroad sleepers U.S. Patent 6,230,981 (2001).

7. Mitchell, R., Baggott, M. G., and Birks, J. "Steel sleepers-an engineering approach to improved productivity", Conf. Railw. Eng. 1987 Prepr. Pap., Institution of Engineers, Australia, p. 131 (1987).

8. Jing, G., Fu, H., and Aela, P. "Lateral displacement of different types of steel sleepers on ballasted track", Constr. Build. Mater., 186, pp. 1268-1275 (2018).

9. Jing, G., Siahkouhi, M., Edwards, J.R., Dersch, M.S., and Hoult, N.A. "Smart railway sleepers-a review of recent developments, challenges, and future prospects", Constr. Build. Mater., p. 121533 (2020).
10. Manalo, A., Aravinthan, T., Karunasena, W., and Ticoalu, A. "A review of alternative materials for replacing existing timber sleepers", Compos. Struct., 92(3), pp. 603-611 (2010).

11. Zakeri, J.A. and Bakhtiary, A. "Comparing lateral resistance to different types of sleeper in ballasted railway tracks", Sci. Iran., 21(1), pp. 101-107 (2014).

12. Jing, G.Q., Aela, P., Fu, H., and Yin, H. "Numerical and experimental analysis of single tie push tests on different shapes of concrete sleepers in ballasted tracks", Proc. Inst. Mech. Eng. Part F J. Rail Rapid Transit, 233(7), pp. 666-677 (2019).

13. Li, B., Li, H., Siahkouhi, M., and Jing, G. "Study on coupling of glass powder and steel fiber as silica fume replacement in ultra-high performance concrete: concrete sleeper admixture case study", KSCE J. Civ. Eng., 24, pp. 1545-1556 (2020).

14. Ferdous, W., Manalo, A., Van Erp, G., Aravinthan,T., Kaewunruen, S., and Remennikov, A. "Composite railway sleepers-Recent developments, challenges and future prospects", Compos. Struct., 134, pp. 158-168 (2015).

15. Adams, J.C.B. "Cost effective strategy for track stability and extended asset life through planned timber sleeper retention", Conf. Railw. Eng. 1991 Demand Manag. Assets; Prepr. Pap., Institution of Engineers, Australia, p. 145 (1991).

16. Ferdous, W., Manalo, A., Van Erp, G., Aravinthan, T., and Ghabraie, K. "Evaluation of an innovative composite railway sleeper for a narrow-gauge track under static load", J. Compos. Constr., 22(2), p. 4017050 (2018).

17. Rothlisberger, E. "History and development of wooden sleeper", Website: < http://www. corbat-holding.ch/ documents/showFile.asp $>$ (2008).

18. Manalo, A., Aravinthan, T., Karunasena, W., and Ticoalu, A. "A review of alternative materials for replacing existing timber sleepers", Composite Structures, 92(3), pp. 603-611 (2010).

19. Yella, S., Dougherty, M., and Gupta, N.K. "Condition monitoring of wooden railway sleepers", Transp. Res. part C Emerg. Technol., 17(1), pp. 38-55 (2009).

20. Zakeri, J. and Bakhtiary, A. "Comparing lateral resistance to different types of sleeper in ballasted railway tracks", Scientia Iranica, 21, pp. 101-107 (2014).

21. Thompson, D.J. and Verheij, J.W. "The dynamic behaviour of rail fasteners at high frequencies", Appl. Acoust., 52(1), pp. 1-17 (1997).

22. Sadeghi, J. and Barati, P. "Comparisons of the mechanical properties of timber, steel and concrete sleepers", Struct. Infrastruct. Eng., 8(12), pp. 11511159 (2012).

23. Song, W., Huang, B., Shu, X., Stránský, J., and Wu, H. "Interaction between railroad ballast and sleeper: a DEM-FEM approach", Int. J. Geomech., 19(5), p. 4019030 (2019). 
24. Ferdous, W. and Manalo, A. "Failures of mainline railway sleepers and suggested remedies-review of current practice", Eng. Fail. Anal., 44, pp. 17-35 (2014).

25. GangaRao, H.V.S., Taly, N., and Vijay, P.V., Reinforced Concrete Design with FRP Composites, CRC press (2006).

26. Ferdous, W., Manalo, A., Khennane, A., and Kayali, O. "Geopolymer concrete-filled pultruded composite beams-concrete mix design and application", Cem. Concr. Compos., 58, pp. 1-13 (2015).

27. Ferdous, W., Khennane, A., and Kayali, O. "Hybrid FRP-concrete railway sleeper", 6th International A CIC Conference, Queen's University Belfast, September 10-12 (2013).

28. Jing, G., Siahkouhi, M., Qian, K., and Wang, S. "Development of a field condition monitoring system in high speed railway turnout", Measurement, 169, p. 108358 (2020).

29. Esmaeili, M. and Siahkouhi, M. "Tire-derived aggregate layer performance in railway bridges as a novel impact absorber: Numerical and field study", Struct. Control Heal. Monit., 26(10), p. e2444 (2019).

30. Esmaeili, M., Ataei, S., and Siahkouhi, M. "A case study of dynamic behaviour of short span concrete slab bridge reinforced by tire-derived aggregates as subballast", Int. J. Rail Transp., 8(1), pp. 80-98 (2020).

31. Wang, G.W. "Properties and utilization of steel slag in engineering applications", Wollongong, $\mathrm{Ph}$. D. Thesis, University of Wollongong (1992).

32. Jing, G. and Aela, P. "Review of the lateral resistance of ballasted tracks", Proc. Inst. Mech. Eng. Part F J. Rail Rapid Transit, 234(8), pp. 807-820 (2020).

33. Tietak, "Composite sleeper", http://www.tietek.net./.

34. A xion-EcoTrax "ECOTRAX® axion composite sleeper mechanical properties", \%3Cwww.axionintl. com $\% 3 \mathrm{E}$.

35. KLP, Lankhorst Rail and Netherlands, "KLP® hybrid polymer sleepers - corporate brochure", \%3Cwww.lankhorstrail.com\%3E.

36. Standard, I. "Plastics - Plastic railway sleepers for railway applications (railroad ties)", ISO 12856 (2014).

37. Lampo, R., Nosker, T., and Sullivan, H. "Development, testing and applications of recycled plastic composite cross ties", US Army Eng. R\&D Cent. (2003).

38. Jimenez, R., Vertical Track Modulus in Plastic Composite Tie Test Zones at FAST, Transportation Research Board (TRID), DOT/FRA/ORD-03/13 (2003).

39. Reiff, R. and Trevizo, C., Cracking and Impact Performance Characteristics of Plastic Composite Ties., United States, Federal Railroad Administration (2012).

40. Vijay, P.V., Hota, G.V.S., Bethi, A., Chada, V., and Qureshi, M.A.M. "Development and implementation of recycled thermoplastic RR ties", Jt. Rail Conf., pp. 209-218 (2010).
41. Lotfy, I. and Issa, M.A. "Evaluation of the longitudinal restraint, uplift resistance, and long-term performance of high-density polyethylene crosstie rail support system using static and cyclic loading", Proc. Inst. Mech. Eng. Part F J. Rail Rapid Transit, 231(8), pp. 835-849 (2017).

42. Moulding, L. "Sustainable plastic sleeper", https:// www.lankhorst-mouldings.com/.

43. Murray, M.H. and Bian, J. "Ultimate limit states design of concrete railway sleepers", Proc. Inst. Civ. Eng., Thomas Telford Ltd, pp. 215-223 (2012).

44. Arema, L.M.D. "American railway engineering and maintenance-of-way association", Man. Railw. Eng., 2, pp. 55-57 (2013).

45. "Static load crack resistance test method for prestressed concrete sleepers (TB/T 1879-2002)", Minist. Railw. (Q72), Academy of Railway Sciences, Institute of Railway Construction (2002).

46. Anurag, S. "Problems in maintenance of Indian railway in deserts and possible solutions", UIC Work. Desert Railw., pp. 67-82 (2008).

47. Luuk van der Drift, V.M. "3- and 4-point bending test of a plastic sleeper" (2018).

48. Silva, É.A., Pokropski, D., You, R., and Kaewunruen, S. "Comparison of structural design methods for railway composites and plastic sleepers and bearers", Australian Journal of Structural Engineering, 18(3), pp. 160-177 (2017).

49. Lam, H.F. and Wong, M.T. "Railway ballast diagnose through impact hammer test", Procedia Eng., 14, pp. 185-194 (2011).

50. Kaewunruen, S. and Remennikov, A.M. "Impact capacity of railway prestressed concrete sleepers", Eng. Fail. Anal., 16(5), pp. 1520-1532 (2009).

51. Kaewunruen, S. and Remennikov, A.M. "Progressive failure of prestressed concrete sleepers under multiple high-intensity impact loads", Eng. Struct., 31(10), pp. 2460-2473 (2009).

52. Brandt, A., Noise and Vibration Analysis: Signal Analysis and Experimental Procedures, John Wiley \& Sons (2011).

53. An, B., Gao, L., Xin, T., Xiang, G., and Wang, J. "A novel approach of identifying railway track rail's modal frequency from wheel-rail excitation and its application in high-speed railway monitoring", IEEE Access, 7, pp. 180986-180997 (2019).

54. ASTM, C. ASTM Standards, American Society for Testing Materials Philadelphia (1958).

\section{Biographies}

Mohammad Siahkouhi is currently a Doctoral student at the Department of Civil Engineering, Beijing Jiaotong University. He obtained a master of science in Railway Engineering from the Iran University of Science and Technology. His research interest includes 
railway engineering, concrete technology, composite structures, and structural health monitoring.

Xinjie Li received her BSc degree in Civil Engineering from Beijing Jiaotong University, Beijing, China, in 2019. She is currently an MSc student in Railway Engineering, Beijing Jiaotong University. Her research interests include analysis of railway track structure and the application of composite materials on the railway track structure.

Valerie Markine obtained his MSc Diploma in Mechanics from Gorky State University, Gorky (now Nizhniy Novgorod), USSR. He obtained his PhD in Mechanical Engineering from the Delft University of Technology. In 1998 he has joined the Section of Road and Railway Engineering, Faculty of Civil Engineering of TU Delft. At present, he works as an Assistant Professor (tenure) at the Section of Railway Engineering.

Guoqing Jing is currently a Full Professor of the Highway and Railway Engineering Department at Beijing Jiaotong University, China. He obtained his PhD degree in Civil Engineering from INSA de Rennes, France. He was invited as a visiting Professor to UIUC, USA, and TUD, Netherland. He has also sided-worked for several companies in the railway industry. He served as a Vice Director of the State Key Lab of Waterproof for China, and Guest Professor for UMP, Malaysia, etc. He is working on a ballasted track, especially recycled and composite materials, and his tools are DEM and FEM. 